LAW, ETHICS, AND MEDICINE

\title{
Balancing confidentiality and the information provided to families of patients in primary care
}

\author{
M D Pérez-Cárceles, J E Pereñiguez, E Osuna, A Luna
}

J Med Ethics 2005;31:531-535. doi: 10.1136/jme.2004.010157

\begin{abstract}
See end of article for authors' affiliations

.....................

Correspondence to: M D Pérez-Cárceles, Department of Legal and Forensic Medicine, School of Medicine, University of Murcia, E-30100

Espinardo, Murcia, Spain; mdperez@um.es
\end{abstract}

Received 26 July 2004

In revised form

11 November 2004

Accepted for publication

15 November 2004

\begin{abstract}
Background: Medical confidentiality underpins the doctor-patient relationship and ensures privacy so that intimate information can be exchanged to improve, preserve, and protect the health of the patient. The right to information applies to the patient alone, and, only if expressly desired, can it be extended to family members. However, it must be remembered that one of the primary tenets of family medicine is precisely that patient care occurs ideally within the context of the family. There may be, then, certain occasions when difficulties will arise as to the extent of the information provided to family members.

Objectives: This study aimed to describe family doctors' attitudes to confidentiality and providing patient information to relatives as well as their justifications for sharing information.

Method: A descriptive postal questionnaire was self-administered by family doctors.

Results: Of 227 doctors, $95.1 \%$ provided information to a patient's family and over a third (35\%) disclosed information to others without prior patient consent.

Conclusions: The findings reveal that family doctors should pay more attention to their patients' rights to information, privacy, and confidentiality, and reflect very carefully on the fine balance between this and the occasional need for the support and collaboration of family members in delivery of care. Emphasis should be placed on ethics and legal problems during undergraduate education and in-service training of doctors.
\end{abstract}

$\mathrm{T}$ he doctor-patient relationship is the primary focus of ethics in medicine. It is both a personal and a professional relationship founded on trust, confidence, dignity, and mutual respect. ${ }^{1}$ Medical confidentiality protects this relationship and ensures privacy so that intimate information can be exchanged to improve, preserve, and protect the patient's health. ${ }^{2}$ Except in certain circumstances, a patient must specifically give consent for disclosure of information about their health care before a treating doctor is at liberty to discuss that information with anyone, including the patient's family. ${ }^{3}$ This doctor-patient relationship is particularly important in primary care.

- A defining characteristic of family medicine is the development of a sustained relationship between patients and doctors over long periods of time. ${ }^{4}$ Family doctors are involved with people before they become ill and they also look after chronically and terminally ill patients. Patients who seek the service of primary care professionals have families, are subject to a series of socioeconomic conditions, and go through a variety of experiences and conflicting situations over time. The doctor's knowledge of the patient's environment helps professional decision making when the need arises.

- One of the primary tenets of family medicine is precisely that patients should be ideally cared for within the context of the family, so that there are numerous occasions when information is exchanged with family members.

- The family doctor is not only the doctor of a given patient but also, probably, of other members of the family. ${ }^{6}$

- Family members may frequently be present during a consultation. $^{78}$

All these circumstances may give rise to several issues of concern that make the doctor-patient relationship in primary care more complex and include the worry or questions asked about a patient's health by family members and the ethical dilemmas involving confidentiality and privacy. ${ }^{9}$

The objective of the present study was to describe attitudes of family doctors towards confidentiality, providing information to relatives, and their justification for any sharing of information.

\section{METHODS}

\section{Type of study}

We conducted a cross-sectional survey. The ethical research committee of the regional health authority approved the study.

\section{Study population}

The size of the sample as initially calculated was 385 with population proportion $=0.5$, precision of $5 \%$, and confidence level $95 \%$. However, our final sample consisted of 227 family doctors, representing a response rate of $59 \%$. Of the 72 primary healthcare centres in the province of Murcia, Spain, $56(77.7 \%)$ responded.

\section{Source and collection of data}

The data were obtained by means of a self-administered, validated questionnaire. The actual questions were formulated in a brain-storming session involving seven family doctors and three university teachers, all recognised experts in the field. To check the internal consistency and thus to validate the questionnaire, it was administered to a further 30 family doctors, who were asked for their comments and suggestions as to how it could be improved. Cronbach's $\alpha$ test was applied to the results $(\alpha=0.87)$.

The first part of the questionnaire consisted of 15 items to define the socio-professional characteristics of the sample (see table 1). To evaluate the information provided by the doctor to families of patients we chose the following questions and possible answers: 
(1) Do you provide information to patients' families?

(a) Yes

(b) No

(2) When providing information to patient's families, do you:

(a) Ask the patient first

(b) Do so without asking the patient first

(c) Only do so in the case of minors

(3) What form does such information take?

(a) Oral

(b) Written

(c) Both oral and written

(4) What type of information do you provide to family members?

(a) Complementary to that offered to the patient

(b) The same information

(c) None

To ascertain the amount of information doctors consider it necessary to give family members we used the three statements given in table 2 (which shows the extent to which the doctors agreed with each, as determined by a Likert scale of $1-4 ; 4=$ highest degree of agreement). The reasons for offering information to family members were explored by the five statements given in fig 1 (which shows the extent to which doctors agreed with each on a Likert scale). We used one item to assess the importance given to confidentiality in different health problems determined by a Likert scale of $1-5(5=$ the most importance $)$.

The questionnaires were mailed to 385 of 554 practising family doctors in the province of Murcia, chosen in a stratified random manner. They were asked to fill in the questionnaires on a voluntary and anonymous basis before returning them to the authors.

\section{Statistical analysis}

The SPSS 11.0 package was used for statistical analysis of the data using simple distribution of frequencies, association between variables (Pearson's $\chi^{2}$ test), and the Kruskal-Wallis test for intergroup comparison.

\section{RESULTS}

\section{Socio-professional characteristics}

The socio-professional characteristics of the sample are summarised in table 1 . Of the professionals who completed the questionnaires most were aged 36-55 years (84.6\%); the number of men comprising the sample was double that of women (64.3\% $v 35.7 \%$, respectively) and most were married $(78.9 \%)$. As regards the length of service, the largest group $(52.4 \%)$ was formed by those who had been in practice for 11-20 years, followed by those who had been in practice for $21-30$ years $(26 \%)$. At the time of filling in the questionnaire, $30 \%$ had been in their present post for less than three years and $26 \%$ between three and five years. Those in their present post for more than 15 years were represented by the lowest percentage $(11 \%)$ of replies. Most doctors $(52.4 \%)$ worked in practices in towns of 5000-15000 inhabitants.

The doctors' professional training had involved an internship specialising in family and community medicine $(49.8 \%)$, specialisation through different courses $(30.4 \%)$, or transfer from other specialties (19.8\%). Most doctors (92.1\%) were exclusively employed in the public sector. The number of patients on each doctor's list varied from 1901 to 2100 for $32.6 \%$, whereas $20.3 \%$ had fewer than 1500 patients. In the

\begin{tabular}{|c|c|}
\hline Age, mean (SD) & $44.2(7.14)$ \\
\hline Men $(\%)$ & 64.3 \\
\hline Married (\%) & 78.9 \\
\hline Years in practice, mean (SD) & $17.8(7.55)$ \\
\hline Years in present post, mean (SD) & $6.5(5.97)$ \\
\hline \multicolumn{2}{|l|}{ Work environment (\%) } \\
\hline Urban (>15000 inhabitants) & 29.1 \\
\hline Semiurban (5000-15000 inhabitants) & 52.4 \\
\hline Rural (<5000 inhabitants) & 18.5 \\
\hline \multicolumn{2}{|l|}{ Previous training (\%) } \\
\hline Family doctor (internship) & 49.8 \\
\hline Family doctor (other ways) & 30.4 \\
\hline Other specialties & 19.8 \\
\hline \multicolumn{2}{|l|}{ Type of practice (\%) } \\
\hline Public & 92.1 \\
\hline Public and private & 7.9 \\
\hline Number of patients on list, mean (SD) & 1786 (295.24) \\
\hline \multicolumn{2}{|l|}{ Number of patients seen daily $(\%)$} \\
\hline $30-40$ patients & 18.9 \\
\hline 41-50 patients & 35.7 \\
\hline $51-60$ patients & 29.5 \\
\hline$>60$ patients & 15.9 \\
\hline $\begin{array}{l}\text { Work in a "training health centre" }(\%) \\
\text { Time dedicated to seeing patients (\%) }\end{array}$ & 49.8 \\
\hline $3-4$ hours & 10.6 \\
\hline$>4-5$ hours & 36.1 \\
\hline$>5-6$ hours & 34.8 \\
\hline$>6$ hours & 18.5 \\
\hline
\end{tabular}

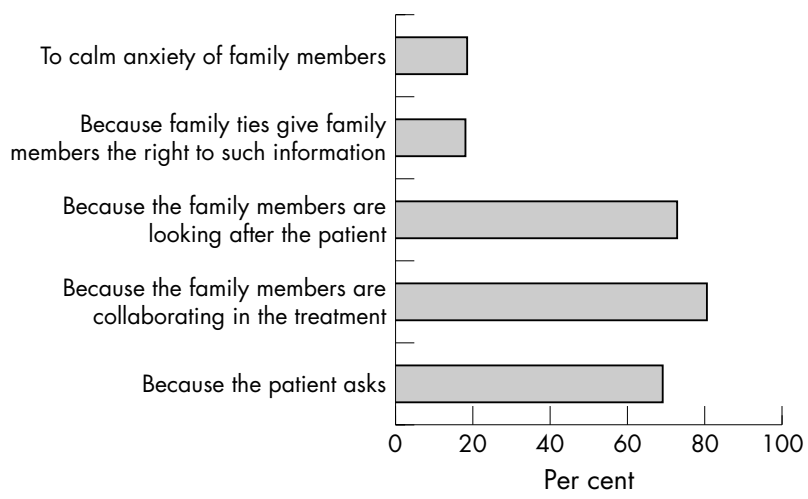

Figure 1 Percentage of family doctors who strongly agreed with the reasons provided for giving information to persons other than patients.

main $(35.7 \%)$, the family doctors saw $41-50$ patients per day. Approximately half the doctors practised in health centres that served as government accredited centres for training family doctors, and $70.9 \%$ dedicated four to six hours per day to seeing patients.

\section{Providing information to relatives}

In the present study $95.1 \%$ of family doctors provided information to a patient's family: $55.9 \%$ only did so after asking the patient for permission but $35.3 \%$ did not think this formality was necessary, and $8.8 \%$ said that they only informed the family if the patient was a minor (less than 18 years of age). The information was provided orally by $89 \%$, and the rest provided both oral and written information. The type of information offered to families was complementary to that offered to the patient $(52.4 \%)$ or the same $(42.7 \%)$, and only $4.9 \%$ did not offer information to family members.

The extent to which doctors agreed with the reasons provided in the survey for offering information to the family 
Table 2 The amount of information relatives should be given: opinion of family doctors

\begin{tabular}{|c|c|c|c|c|}
\hline & $\begin{array}{l}\text { Total } \\
\text { disagreement } \\
\text { n (\%) }\end{array}$ & $\begin{array}{l}\text { Partial } \\
\text { disagreement } \\
\text { n (\%) }\end{array}$ & $\begin{array}{l}\text { Partial } \\
\text { agreement } \\
\text { n (\%) }\end{array}$ & $\begin{array}{l}\text { Total } \\
\text { agreement } \\
\text { n (\%) }\end{array}$ \\
\hline $\begin{array}{l}\text { Relatives should be given only the information that will enable them to help the patient } \\
\text { Relatives should be given only the information that the patient cannot assume or accept } \\
\text { Relatives should be given information only when the patient is incapable of understanding it }\end{array}$ & $\begin{array}{l}24(10.6) \\
8(3.5) \\
7(3.1)\end{array}$ & $\begin{array}{l}43(18.9) \\
7(3.1) \\
8(3.5)\end{array}$ & $\begin{array}{l}101(44.5) \\
108(47.6) \\
66(29.1)\end{array}$ & $\begin{array}{l}59(26) \\
104(45.8) \\
146(64.3)\end{array}$ \\
\hline
\end{tabular}

is depicted in fig 1 , and the amount of information doctors consider family members need is shown in table 2 .

Table 3 presents a profile of the family doctors who did not consider it necessary to ask their patients' permission before providing information to family members.

\section{Evaluation of importance of confidentiality}

The means (confidence intervals) of how the family doctors valued confidentiality with respect to different aspects of health, as determined by a Likert scale, were as follows: 4.52 (4.40 to 4.64$)$ for sexuality, 3.98 (3.83 to 4.13$)$ for illegal drugs, 3.76 (3.61 to 3.96) for legal drugs, 3.62 (3.47 to 3.77) for chronic illnesses, 3.59 (3.43 to 3.76) for mental illnesses, 3.55 (3.38 to 3.72) for acute illnesses, and 3.28 (3.11 to 3.44) for eating habits.

The importance given to confidentiality by the professionals surveyed as regards certain aspects of health care is summarised in fig 2. Sexual matters were considered important or very important by $92.5 \%$ of doctors and food related issues were given the least importance (39.7\%).

We found statistically significant differences when evaluating confidentiality in the context of the socio-professional variables used to characterise the family doctors. The greatest degree of confidentiality was given to sexual matters by male $(p=0.007)$, separated $(p=0.0016)$ doctors who work in a rural environment $(\mathrm{p}=0.001)$ and who had trained as family doctors $(p=0.001)$, with less than 1500 patients on their lists $(p=0.005)$. Age, too, resulted in statistically significant differences. Those over 55 gave more importance to confidentiality in eating habits $(p<0.001)$, acute illnesses $(p<0.001)$, chronic illnesses $(p<0.001)$, and mental illnesses $(\mathrm{p}<0.001)$.

\section{DISCUSSION}

The family doctors comprising our survey sample are representative of the general situation of the profession in Spain. They were mainly men, of middle age, married, and had children. They were at the height of their careers with a wealth of experience, mainly working in semiurban or rural

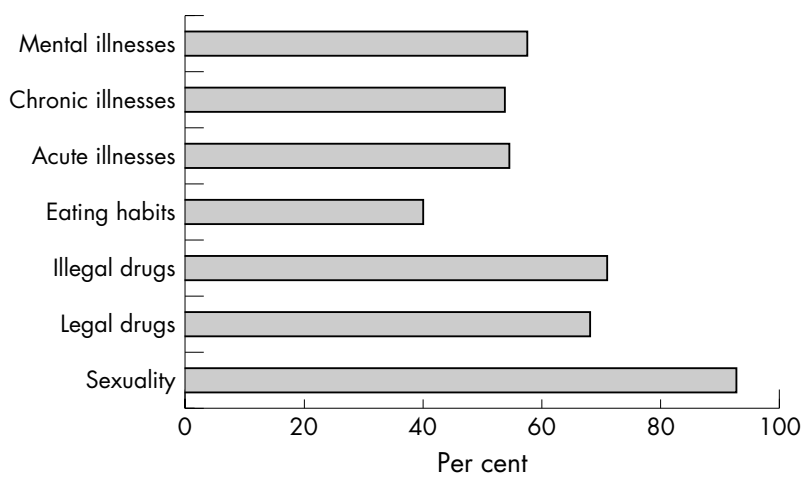

Figure 2 Percentage of family doctors who give much importance to confidentiality in different health matters.

communities and solely for the local health service. Their workload might be considered excessive, as judged from the high number of patients on their lists and the large number of patients seen every day. This had a negative effect on other types of activity that might also be considered as within the competence of primary care doctors. ${ }^{10}$

A new law in Spain (41/2002) concerned with patients' rights and doctors' obligations in matters of clinical information and documentation, clearly specifies that the owner of such information is the patient. However, the law also states that people associated with the patient, either by family ties or more informal ones, may also be informed to the extent that the patient wishes. Article 7 of the law, which states that it is a right of every person that the confidential nature of data referring to his or her health be respected and that no-one can have access to such information without the patient's permission, reinforces the patient's right to privacy. However, it is clear from the results of our analysis that almost all family doctors provide information to family members and that over a third (35\%) will disclose information to others without prior consent, implying that a high percentage are breaking the law. Medical information should

Table 3 Characteristics of family doctors who did not consider it necessary to ask their patients' permission before providing information to family members

\begin{tabular}{lll}
\hline & Per cent & Probability (p value) \\
\hline Age 46-55 years & 50 & $<0.001$ \\
Single & 57.1 & 0.046 \\
More than 20 years spent as a doctor & 41.7 & 0.001 \\
Rural work environment & 40.5 & 0.0264 \\
Previous training: other specialties & 48.9 & 0.0324 \\
Number of patients on list: $>2000$ & 40 & 0.007 \\
Number of patients seen daily: $>60$ patients & 38.9 & $<0.001$ \\
3-4 hours spent seeing patients & 66.7 & $<0.001$ \\
Did not work in a training centre & 40.9 & 0.008 \\
Relatives should be given the information only when the patient is & 62.5 & 0.001 \\
incapable of understanding it & & \\
Most used reason for informing families: Family ties imply rights & 50 & 0.001 \\
which outweigh patients' privacy & & \\
\hline
\end{tabular}


only be shared with family members with the patient's consent, and ignoring this could result in a finding of professional misconduct. ${ }^{3}$

Family doctors cite basically two reasons for providing family members with information concerning a patient: (a) because the family members are collaborating in the patient's treatment or $(b)$ because they are caring for the patient. A small number of doctors justify the provision of information because family ties provide certain rights over the patient or because they wish to calm the anxiety of relatives, since ignorance of such information might cause concern. We are of the opinion that family or emotional ties do not constitute a right in itself over and above what a patient might decide at a given moment.

The professional profile of the family doctor who does not consider it necessary to ask for the patient's permission before disclosing information is typically that of a doctor with more than 20 years' service, aged over 45 with a heavy workload (more than 2000 patients on their list and seeing more than 60 patients/day), and dedicating the least time to patients (three to four hours/day), which limits the time available per patient. Other characteristics of these doctors are firstly, they are not specialists in family and community medicine but have transferred from other specialties, and secondly, they do not work in centres providing training to new doctors, both of which strongly suggest that the ethical and legal aspects of the profession are better covered in family medicine courses. The same doctors mostly work in rural practices, where it is much more probable that they also attend to various members of the same family making it easier to share information without giving proper consideration to the matter. Indeed, the reason given for sharing information is precisely that family ties give a right to receive such information.

Lack of confidentiality is a major deterrent to good health care and one of the main reasons that patients are reluctant to divulge information. ${ }^{11}$ However, it is true that many people visit family doctors in the company of relatives or friends. ${ }^{56}$ This might seem to be a good idea since (a) the family context serves to illuminate patient disease, illness, and health, (b) family members might reveal the source of the illness, (c) discussing illness with friends and relations sometimes helps, $(d)$ the family is probably deeply concerned about the patient's health, and $(e)$ the family probably acts as a care resource and collaborator. ${ }^{5}$ However, the patients do not know in advance what questions the doctor will ask. In such a situation, patients may not wish to discuss sensitive topics (such as sexual habits, abortion, alcohol use, or usage other drugs) or even ostensibly trivial topics, ${ }^{12}$ since it is known that patients speak much more freely when on their own. ${ }^{13}$ The doctor must be careful to avoid potential breach of patient confidentiality when discussing diagnoses and treatment decisions in the presence of family members. ${ }^{9}$

In general, doctors seem sufficiently concerned about the confidentiality of their patients. However, there are differences as regards the relative importance doctors give to different health related issues. The area where confidentiality is most respected is that of sexuality. It should be remembered that a high percentage of patients seek advice on matters related to sexual health, where confidentiality is one the most important factors in choosing the particular branch of the health service. ${ }^{14}$ By ensuring confidentiality and maintaining professionalism a doctor will create the trusting, comfortable environment necessary for the thorough evaluation of a patient's sexual health risks. ${ }^{15}{ }^{16}$

The second most important area where doctors respect the need for confidentiality is the consumption of illegal or legal drugs. In the case of substance abuse, the emphasis on confidentiality goes beyond that of general health care. ${ }^{17}$ Food habits are regarded by doctors as being of the least importance as far as confidentiality is concerned.

In general, then, there is a need to revise and improve procedures for the maintenance of confidentiality in primary care. $^{18}$

Although it is a commonplace in primary care that treating an individual with a disease really means treating the family, traditional limitations as regards the scope of confidentiality sometimes seem to have been pushed too far. Perhaps it is time that family doctors paid more attention to their patients' rights to privacy. Family doctors should inform their patients that limited amounts of confidential information may need to be shared with other members of their family, and only that information necessary and relevant to the treatment of the problem will be shared. ${ }^{2}$ Doctors should be trained in psychosocial and discretionary skills to enable them to recognise those patients who need support and will feel more comfortable in the presence of a family member in the surgery. ${ }^{12}$

Our survey shows that certain socio-professional characteristics of family doctors significantly affect the degree of privacy and confidentiality that a patient will receive. We found that sexuality is the most respected area, although statistically significant differences existed between doctors in this matter-family medicine specialists with a low workload and working in smaller rural centres respect confidentiality to a greater extent, despite the abovementioned greater likelihood of contact with other family members. It seems that, in this matter, they are more aware of the impact that the diffusion of this type of information might have.

In Spain, family doctors have a high work load and large numbers of patients on their lists. This has led to the formation of both internal and external pressure groups demanding that at least 10 minutes be allowed for each consultation and that doctors should have no more than 1500 patients, thus permitting them to discharge their professional obligations in a better way. ${ }^{18}$ It is interesting that the doctors who considered it necessary to seek the patient's permission before providing information to family members and those who assigned greater importance to confidentiality in our survey were precisely those with a lighter work load.

\section{Limitations of the study}

Since no similar studies are available in the referenced literature for Spain, our findings cannot be compared with elsewhere. In addition, the study was limited to public sector medicine and therefore the findings cannot be extrapolated to private practice.

\section{CONCLUSIONS}

Our results suggest that family doctors should pay more attention to their patients' rights to information, privacy, and confidentiality, and that they should reflect very carefully on the fine balance between this and the occasional need for the support and collaboration of family members in offering care. There are socio-professional factors too (principally excessive workload and previous training) that can be improved by health service managers and which seem to have a negative effect on patients' rights to privacy. We agree with Shrier et $a l^{11}$ that emphasis should be given to ethics and legal problems during undergraduate education and in-service training.

\section{ACKNOWLEDGEMENT}

We thank Professor D Pérez-Flores for his help in checking the statistical analysis. 


\section{Authors' affiliations}

M D Pérez-Cárceles, E Osuna, A Luna, Department of Legal and Forensic Medicine, School of Medicine, University of Murcia, Murcia, Spain

J E Pereñiguez, Health Center in Espinardo, Murcia, Spain

\section{REFERENCES}

1 Clark P. Confidentiality and the physician-patient relationship-ethical reflections from a surgical waiting room. Med Sci Monit 2002;8:SR31-4.

2 Murray JP. New concepts of confidentiality in family practice. J Fam Pract 1986;23:229-32.

3 Tremayne-Lloyd T. Confidentiality. Disclosure to a patient's family. Can Fam Physician 2003:49:300-1.

4 Parchman ML, Burge SK. The patient-physician relationship, primary care attributes, and preventive services. Fam Med 2003;36:22-7.

5 Main DS, Holcomb S, Dickinson P, et al. The effect of families on the process of outpatient visits in family practice. J Fam Pract 2001;50:888.

6 Medalie JH, Zyzanski SJ, Langa D, et al. The family in family practice: is it a reality? J Fam Pract 1998;46:390-6.

7 Brown JB, Brett P, Stewart M, et al. Roles and influence of people who accompany patients on visits to the doctor. Can Fam Physician 1998:444:1644-50.
8 Cole-Kelly K, Yanoshik MK, Campbell J, et al. Integrating the family into routine patient care: a qualitative study. J Fam Pract 1998;47:440-5.

9 Lang F, Marvel K, Sanders D, et al. Interviewing when family members are present. Am Fam Physician 2002;65:1351-4.

10 Sobreques J, Cebria J, Segura J, et al. Job satisfaction and burnout in general practitioners. Aten Primaria 2003;31:227-33.

11 Shrier I, Green S, Solin J, et al. Knowledge of and attitude toward patient confidentiality within three family medicine teaching units. Acad Med 1998:73:710-12

12 Bewley S. Family secrets. Patients have right to privacy and confidentiality. BMJ 1997;315:1380

13 Barnett A, Stott S. Family secrets. Most patients speak more freely when on their own. BMJ 1997;315:1380.

14 Doherty L. New approaches to sexual health services in a rural health board area: involving service users and primary care professionals. Int J STD AIDS 2000;11:594-8.

15 Peck SA. The importance of the sexual health history in the primary care setting. J Obstet Gynecol Neonatal Nurs 2001;30:269-74.

16 Graham A. Sexual health. Br J Gen Pract 2004:54:382-7.

17 Warner EA, Walker RM, Friedman PD. Should informed consent be required for laboratory testing for drugs of abuse in medical settings? Am J Med 2003;115:54-8.

18 Petchey R, Farnsworth W, Heron T. The maintenance of confidentiality in primary care: a survey of policies and procedures. AIDS Care $2001 ; 13: 251-6$ 